\title{
OIL SPILL SORPTION USING CARBONIZED PITH BAGASSE. APPLICATION OF CARBONIZED PITH BAGASSE AS LOOSE FIBER
}

\author{
M. HUSSEIN ${ }^{1}$ \\ A.A. AMER ${ }^{2, *}$ \\ Is.Ib. SAWSAN ${ }^{2}$
}

\author{
${ }^{1}$ Alexandria University Faculty of Engineering \\ Chemical Department, Alexandria, Egypt \\ ${ }^{2}$ Alexandria Petroleum Company Alexandria, Egypt
}

Received: 01/04/08

Accepted: 10/06/08 *to whom all correspondence should be addressed: e-mail: amer_abdelrazik@yahoo.com

\begin{abstract}
Recent oil tanker accidents in the sea are very serious, not only since they pollute the environment but also because they release heavy oil. The preparation of activated carbon from agricultural waste increases economic return and reduces pollution.

On carbonized fibers, sorption capacity for different kind of oils was determined. Fibers extracted from bagasse and carbonized at $300{ }^{\circ} \mathrm{C}$ for $2 \mathrm{hr}$ were found to have a high performance for sorption, recovery and recycling of heavy oils, even the viscous ones. Sorption capacity showed strong dependence on the weight of sorbent and oil film thickness. Their recycling performance was excellent as they can be used for six cycles until they reach $50 \%$ of the sorption capacity of the $1^{\text {st }}$ cycle.

Comparison between the prepared carbonized fiber and a commercial sorbent has been done and showed that the prepared sorbent could be used as sufficient sorbent more than the commercial sorbent used.
\end{abstract}

KEYWORDS: Oil spill; Sorbent; Carbonization; Loose fiber; Heavy oil; Oil Recovery.

\section{INTRODUCTION}

Oil pollution, particularly of sea and navigable waters, has excited more public concern than any other waste or spilt material. Oil pollution of the sea has steadily increased with the increased oil consumption. The total annual influx of petroleum hydrocarbons is about 10 million metric tons. The bulk of this influx is due to transportation related activities. Oil pollution of the shore, in addition to the reduction of amenity, also affects marine and shore life and vegetation (Wardley-Smith, 1983).

Crude oil spilt in the marine environment undergoes a wide variety of weathering processes, which include evaporation, dissolution, dispersion, photochemical oxidation, microbial degradation, adsorption onto suspended materials, agglomeration, etc (Jordan and Payne, 1980). These physico-chemical changes enhance oil dissolution in seawater (Payne and Phillips, 1985). Previous studies show that photo oxidation of oil in the aquatic environment leads to the formation of numerous oxygenated products such as aromatic, aliphatic, benzoic and naphthanoic acids, alcohols, phenols and aliphatic ketones (Payne and Phillips, 1985; Kawahara, 1969; Frankenfeld, 1973; Larson et al., 1977).

Some of these products like aromatic and aliphatic acids, medium-molecular-weight aromatic alcohols and ethers are water-soluble. The most toxic affect is caused by water-soluble aromatic derivatives of the spilled crude oil. Adult marine organisms do not survive after exposure to $1-100 \mathrm{ppm}$ of soluble aromatic, and for larvae the lethal dose is $0.1 \mathrm{ppm}$. Even sub lethal doses (10-100 ppb) of these compounds disrupt chemical sensing and communication system of marine organisms. 
The methods commonly used to remove oil involve oil booms, dispersants, skimmers, sorbents etc. The main limitations of some of these techniques are their high cost and inefficient trace level adsorption (Wardley-Smith, 1983).

Also most of the dispersants are often inflammable and cause health hazards to the operators and potential damage to fowl, fish and marine mammals. They can also lead to fouling of shorelines and contamination of drinking water sources (National Research Council-NRC, 1989).

So far, some porous polymers, such as poly (propylene) and poly (urethane) mats have been used for the absorption of spilled oil. Their maximum absorption capacity is about $10-30 \mathrm{~g}$ of heavy oil per $1 \mathrm{~g}$ of polymer (Choi and Cloud, 1992).

However, they absorb water as well as heavy oil and show no special selectivity for heavy oils, and so the effective absorption capacity of the polymers for heavy oils floating on water must be lower than the figures mentioned above. Some natural sorbents prepared from cotton fiber, milkweed floss and kenaf plants were reported to have rather high sorption capacities and potential for oil recovery and sorbent reusability (Choi and Cloud, 1992; Johnson et al.,1973; Yamamoto, 1998; Miyata, 1999).

In our previous paper (Amer and Hussein, 2006), a very high sorption capacity of carbonized pith bagasse for different kind oils floating on water was reported.

Carbonized pith bagasse has several advantages: (1) Very high sorption capacity up to 19.04 $\mathrm{g}$ of heavy oil, with relatively low viscosity, per $1 \mathrm{~g}$ of carbonized pith bagasse; (2) Very high rate of sorption, within $15 \mathrm{~min}$; (3) Selective sorption of oils, which spilled into water. In the present work several kind oils differing in their viscosity and density, i.e. gas oil, one and seven day weathered heavy Arabian oil were used. Considering the factors such as the effect of weight of carbonized pith bagasse, oil film thickness, desorption time and the effect of reusability on the sorption capacity of the carbonized pith bagasse were chosen for the current investigations.

The aim of the present work was to prepare carbonized pith bagasse according to the best carbonization condition obtained (Amer and Hussein, 2006) and to determine their sorption ability of removing the oil under different system conditions and to compare between the prepared pith bagasse with a commercial sorbent.

\section{EXPERIMENTAL METHODS}

\subsection{Materials}

\subsubsection{Sorbent material}

The pith bagasse used in this study was a waste produced from sugar industry. Its moisture content was found to be about $40 \%$. The fresh bagasse was thoroughly washed with water to remove soil and other foreign materials. The big part of pith was separated from the tough (hard walled) dried for 7 days under sunlight, dried at $105^{\circ} \mathrm{C}$ for 2 hours, crushed in a Willey mill and sieved. The fraction particle size between $1 \mathrm{~mm}$ and $0.8 \mathrm{~mm}$ was selected and then subjected to a carbonization process in a closed carbonized stainless steel tube (with a length of $12.5 \mathrm{~cm}$, inner diameter of $2.5 \mathrm{~cm}$ and a small hole at the top for the ventilation of the gases produced during carbonization) and heated in a muffle furnace at $300{ }^{\circ} \mathrm{C}$ for $2 \mathrm{hr}$ (Amer and Hussein, 2006).

The commercial sorbents (Adsorbe-IT filtration fabric and Oil-only sorbent) obtained from Canada and The United States have the specifications as shown in Table 1.

\subsubsection{Tested oils}

Different kinds of oils to represents a wide variety, were tested in the application of sorbents. Gas oil has a specific gravity of 0.82 at $T=15^{\circ} \mathrm{C}$ a flash point of $55^{\circ} \mathrm{C}$ obtained from fuel station; heavy Arabian crude oil which has a kinematic viscosity of $11.2 \mathrm{cSt}$ at $40^{\circ} \mathrm{C}$ and a specific gravity of 0.8825 at (60/60) was obtained from Medore Refining Company; fuel oil which has a kinematic viscosity of $445 \mathrm{cSt}$ at $50{ }^{\circ} \mathrm{C}$ was obtained from Alexandria Petroleum Company. The gas and fuel oil were used without modification.

In early stages of an oil spill lighter hydrocarbons do evaporate and consequently the oil viscosity increase before any possible cleanup operation can take place. So in order to simulate this situation of oil spill and to minimize experimental variation, crude oil samples were put on a tray where oil formed a layer of a $5 \mathrm{~mm}$ thick and was situated in open air for 
one and seven days (Stlver and Meck, 1984). Different types of oils, namely gas oil, one and seven day weathered Heavy Arabian crude oil, were employed to investigate the oil sorption characteristics of pith bagasse. Gas oil represents low viscosity $\left(7.46118 \mathrm{cSt}\right.$ at $\left.25^{\circ} \mathrm{C}\right)$ oils such as light crude oil, kerosene and gasoline. One day weathered heavy Arabian crude oil is a good surrogate for oils with intermediate viscosity $\left(181.360 \mathrm{cSt}\right.$ at $\left.25^{\circ} \mathrm{C}\right)$ and a density of $\left(0.856 \mathrm{~g} \mathrm{~cm}^{-3}\right)$ such as heavy crude oil and vegetable oils. Seven day weathered heavy Arabian crude oil represents highly viscous oils $\left(512.79 \mathrm{cSt}\right.$ at $\left.25^{\circ} \mathrm{C}\right)$ and a density of $(0.8954$ $\mathrm{g} \mathrm{cm}^{-3}$ ) such as lubricating oils. These oils were investigated in favor of the crude oils or lightweight hydrocarbon oils because they were less volatile and had better compositional uniformity, which minimized transient change in their chemical and physical characteristics during experiments.

Table 1. Commercial sorbents specifications

\begin{tabular}{llll}
\hline Type & $\begin{array}{l}\text { Company and country } \\
\text { of manufacturing }\end{array}$ & Composition & Thickness \\
\hline $\begin{array}{l}\text { Adsorbe-IT filtration } \\
\text { fabric }\end{array}$ & ECO-TECH, Inc, USA & $\begin{array}{l}\text { Geo-textile quality } \\
\text { nonwoven filtration fabric } \\
\text { manufacture from 100\% } \\
\text { recycled selected fiber } \\
\text { from textile industry. }\end{array}$ & 0.69" \\
\hline Oil-only sorbent & $\begin{array}{l}\text { ARCUS absorbent Inc, } \\
\text { Toronto, Ontario, } \\
\text { Canada }\end{array}$ & $\begin{array}{l}\text { Hydrophobic polypropylene } \\
\text { product available pad }\end{array}$ & $3.73 \mathrm{~mm}$ \\
\hline
\end{tabular}

\subsection{Methodologies of oil sorption experiments}

\subsubsection{Determination of dynamic oil retention and oil sorption capacity}

A $500-\mathrm{mL}$ sample of artificial seawater $(3.5 \% \mathrm{NaCl})$ was placed in a 1-L glass beaker, as described in Technical Manual of the American Association of Textile Chemists and Colorists [AATCC] (Choi and Cloud, 1992). A forty $\mathrm{ml}$ of oil was added to the beaker. The beaker containing crude oil and artificial sea water was mounted in a shaking apparatus. Approximately one gram of a sorbent material was placed in the system, which was shaking for 15 minutes at 105 cycles $\mathrm{min}^{-1}$. The wetted sorbent material was weighed after being drained for $5 \mathrm{~min}$ in the sustainer. Water content of the sorbent was analyzed by the ASTM D4007-81 (ASTM, 1998 a).Petroleum ether was used as the carrier solvent. The amount of oil sorbed by the sorbent was determined by subtracting the water content and the initial sorbent weight from the total weight of wetted sorbent.

Oil sorption capacity $=\left[\mathrm{S}_{\mathrm{T}}-\mathrm{S}_{\mathrm{C}}-\mathrm{S}_{\mathrm{A}}\right] / \mathrm{S}_{\mathrm{A}}$

Where $S_{A}$ is the dry weight of the sorbent $(\mathrm{g}), S_{T}$ is the total weight $(\mathrm{g})$ of the oil, water and dry sorbent, and $\mathrm{S}_{\mathrm{C}}$ is the weight of water $(\mathrm{g})$.

\subsubsection{Evaluation of cyclic sorption/desorption characteristics}

This experiment evaluated reusability of the pith bagasse fiber for cyclic oil sorption/desorption. The experiments were carried out under simulated field conditions, as described above.

The procedure was similar to that adopted by Inagaki (Inagaki et al., 2002) with modification on their oil recovery method. Using filtration under mild suction (by using a vacuum pump) of the sorbed carbonized pith bagasse, oils could be recovered without serious disruption of the bulky morphology of carbonized pith bagasse. The sorption/desorption cycle was repeated for the desired number of cycles until oil sorption capacity was less than $50 \%$ of the sorbed oil in the first cycle. 


\section{RESULTS AND DISCUSSIONS}

\subsection{The effect of weight of carbonized pith bagasse}

The oil sorption characteristics of carbonized pith bagasse in the oil-over-water baths with different amounts of sorbent are illustrated in Figures 1 and 2, respectively. The amounts of water pickup are also shown, which allow indication of sorbent selectivity between oils and water. This quantification has not been available in the published literature for most of the oil sorbents investigated.

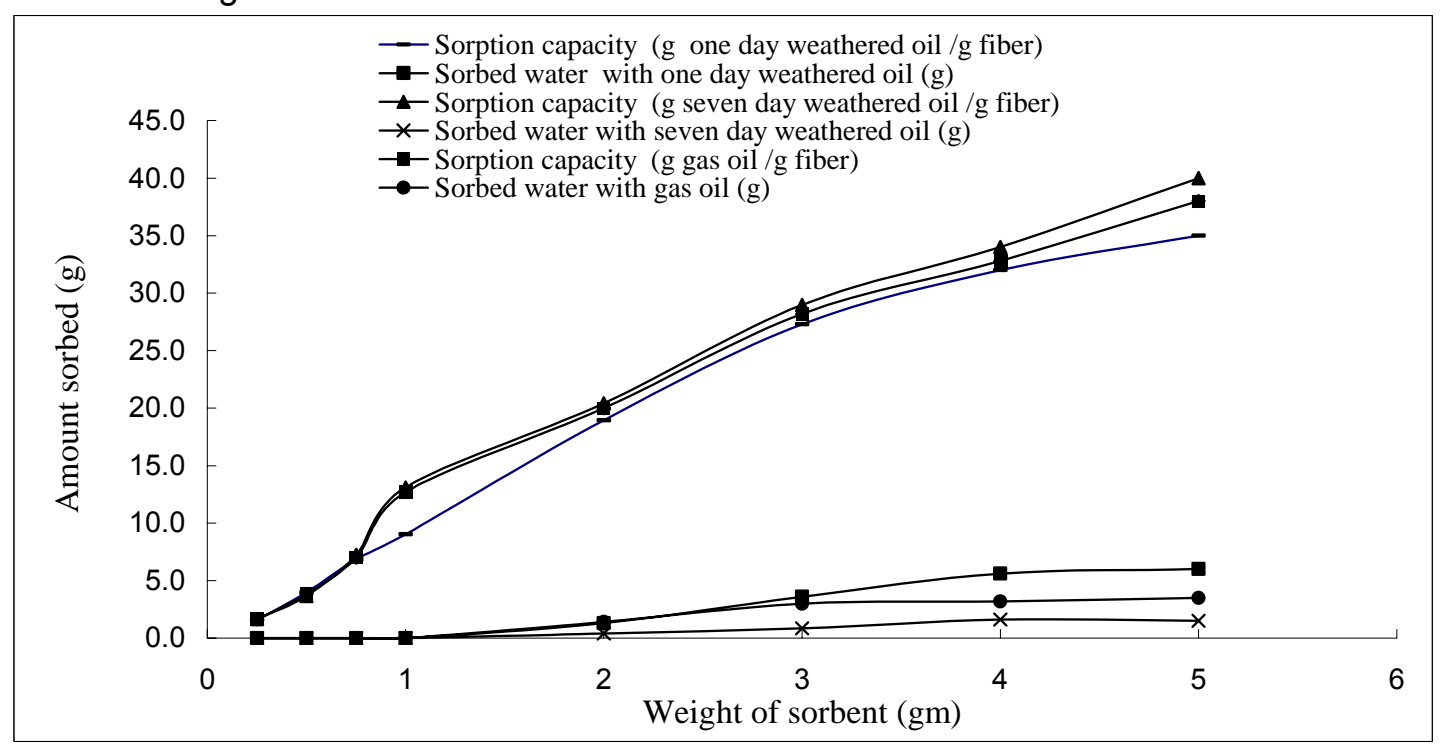

Figure 1. Effect of weight of sorbent on the amount of sorbed oil and water.

Figure 1 shows that as the weight of carbonized pith bagasse fiber increases amount of sorbed oil till all oil film on the water surface sorbed [disappear] at fiber weight $3 \mathrm{~g}$.

The seven day weathered crude oil has the highest oil amount of $(38 \mathrm{~g})$ at a weight of sorbent of $(3 \mathrm{~g})$ then one day weathered oil has a sorption capacity of $(37 \mathrm{~g})$ at a weight of sorbent of $(3 \mathrm{~g})$ and the gas oil has the lowest sorption capacity of $(31.09 \mathrm{~g})$ at a weight of sorbent of (3 g).

In earlier stage from 0.25-3 gram the sorbent surface area contact to oil was the maximum so the amount oil sorbed was maximum; due to sorbent surface area, and the channels formed between particle due to random distribution of particle and irregular surface shape.

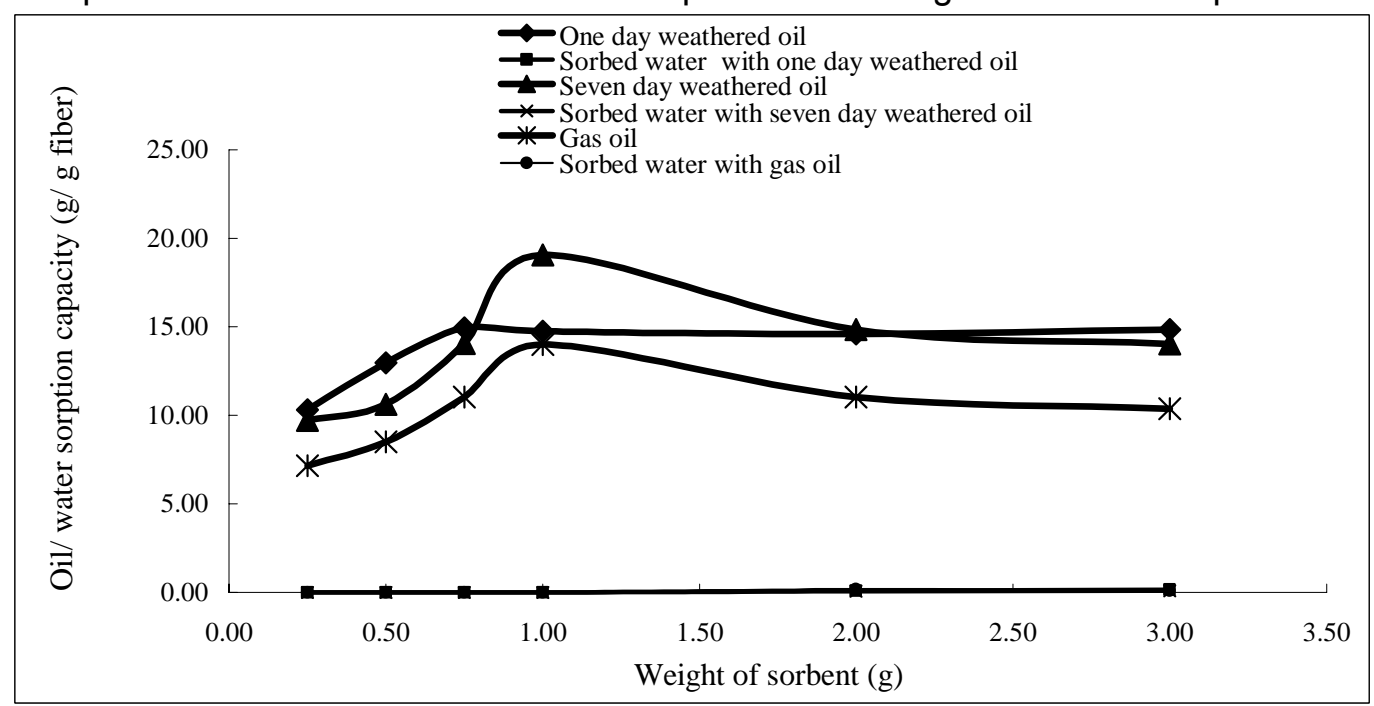

Figure 2. Effect of weight of sorbent on the sorption capacity ( $\mathrm{g} \mathrm{g}^{-1}$ of fiber) 
Figure (2) shows that as the carbonized fiber weigh increased the sorption capacity $\left(\mathrm{g} \mathrm{g}^{-1}\right.$ fiber) increased to maximum oil sorption capacity at one $g$ then decreased. Seven day weathered crude oil has the highest sorption capacity of (19.06 oil g ${ }^{-1}$ of fiber) at weight of sorbent of $(1 \mathrm{~g})$ then it decreases to a constant value; the one day weathered oil has the second highest sorption capacity of $\left(14.74 \mathrm{~g} \mathrm{oil} \mathrm{g}^{-1}\right.$ of fiber) at weight of sorbent of $(1 \mathrm{~g})$ then it decreases to a constant value but the gas oil has the lowest sorption capacity; it still increases till reaches a constant value of ( $14 \mathrm{~g}$ oil g ${ }^{-1}$ fiber).

\subsection{The effect of the oil film thickness}

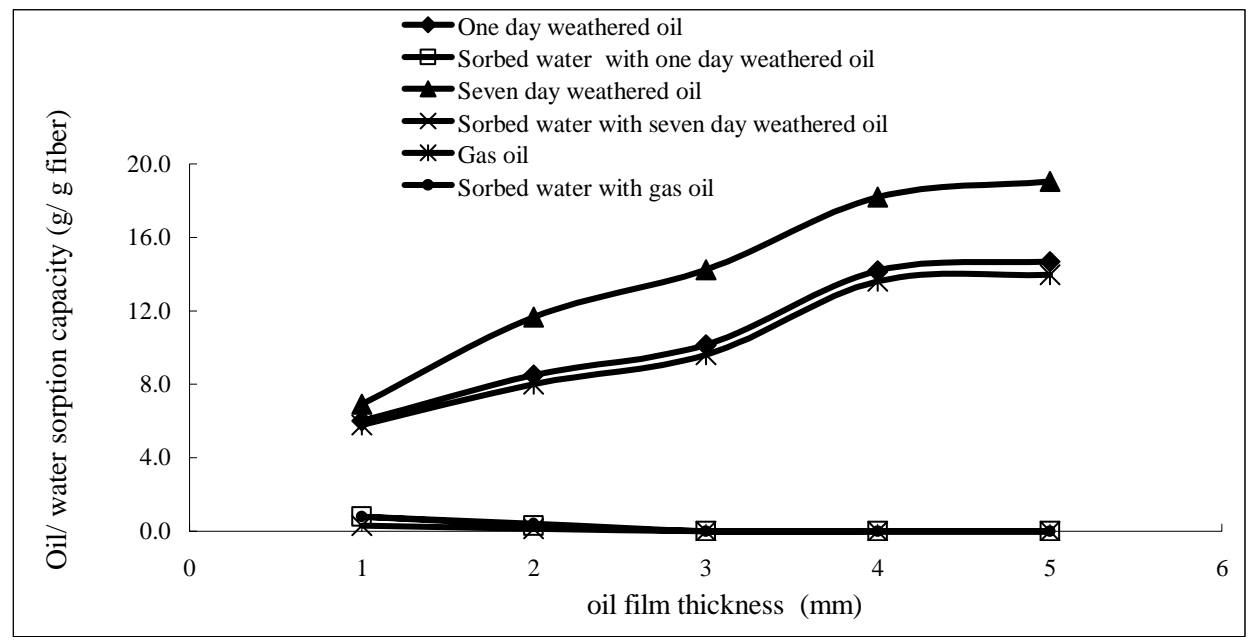

Figure 3. Effect of oil film thickness on the sorption capacity ( $g \mathrm{~g}^{-1}$ fiber)

Figure 3 shows that the sorption capacity increases by increasing the oil film thickness. Also it shows that the water pick-up decreases by increasing the oil film thickness until it reaches the lowest value of $\left(0 \mathrm{~g}\right.$ water $\mathrm{g}^{-1}$ fiber) for all types of oil at film thickness of $(5 \mathrm{~mm})$. The figure also shows that the seven day weathered crude oil has the highest sorption capacity until it reaches a maximum value of $\left(19.06 \mathrm{~g}_{\text {oil g }} \mathrm{g}^{-1}\right.$ of fiber) at oil film thickness of $(5 \mathrm{~mm})$ then it is followed by the one day weathered crude oil which has the second highest sorption capacity of (14.74 $\mathrm{g}$ oil $\mathrm{g}^{-1}$ of fiber) at film thickness of $(5 \mathrm{~mm})$; finally the lowest sorption capacity is for which is (14 $\mathrm{g}$ oil $\mathrm{g}^{-1}$ of fiber) at oil film thickness of $(5 \mathrm{~mm})$.

The result indicates that the sorption capacity of pith bagasse is enhanced by increase the oil film thickness, the water pickup are decrease to a small value. The oil film contact sorbent surface to oil is the maximum and inhibits sorbent contact to water to minimum value. i.e., the oil sorption capacity increases as the amount of oil increases.

These results are in agreement (Inagaki et al., 2000) as they have studied the effect of thickness of the oil layer.

\subsection{The effect of desorption time on the holding capacity}

Figure 4 shows that the dripping of oil from the surface of the carbonized pith bagasse is fast during the first 5 min then it approximately stops, except for the dripping of gas oil, which is very small.

These results are in agreement with those reported by Choi and Kwon (1993) as they investigated the kinetics of oil desorption. In addition, the results are in agreement with Lim and Huang (2007) and with Wei et al. (2003); the results show that the retention behavior of all sorbents follows almost the same trend. There are at least two distinct zones in each retention curve. The first zone is the initial stage of release, which occurs over the five minutes. The rate of release is very high during this period. The second zone represents the steady-state period. During this period, the sorbent tends to begin a descent toward a steady state. In this zone, additional time will not release any significant amount of oil. However, although the sorption retention curves for all sorbents show similar trends, they also exhibit many varied phenomena. Light oil tends to be released from sorbent fast with high release rate compared to the heavy oil. 


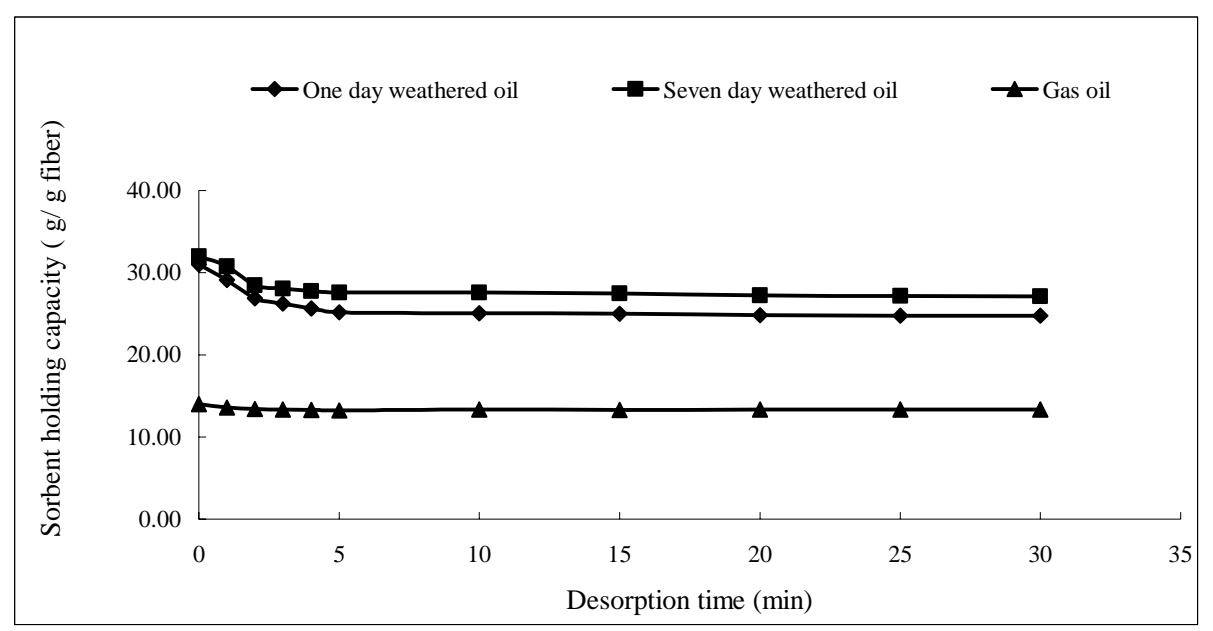

Figure 4. Effect of desorption time on the holding capacity ( $\mathrm{g} \mathrm{g}^{-1}$ of fiber)

\subsection{The effect of the reusability}

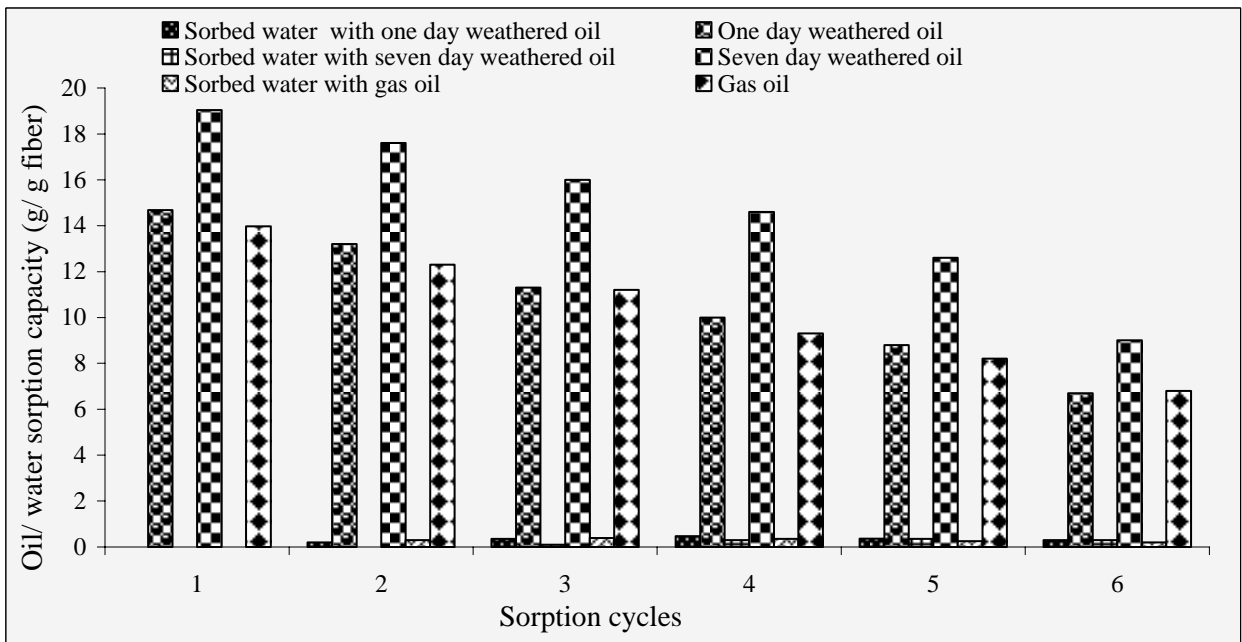

Figure 5. Effect of reusability on the sorption capacity ( $\mathrm{g} \mathrm{g}^{-1}$ of fiber).

Figure 5 illustrates that oil sorption capacity decreases during repeated use.

The recovery of oil was found to decrease and the results suggest that pith bagasse can be reused several times for oil spill cleanup with the aid of a vacuum pump.

The figure also shows that the seven day weathered crude oil has the highest sorption capacity then one day has the second highest sorption capacity and finally the gas oil has the lowest sorption capacity. The sorption capacity decreases until it reaches the lowest value at the sixth cycle for all oil tested.

In practical oil spill cleanup operation on the water, oil is removed from the sorbent by a simple mechanical action (where the vacuum used) and the sorbent is reapplied several times.

If the carbonized pith bagasse was squeezed after sorbing heavy oil up to its maximum capacity, a large amount of the oil would come out by simple compression.

However, the characteristic bulky morphology of the carbonized pith bagasse would be destroyed. As a consequence, there was no possibility of recycling the carbonized pith bagasse by compression. Therefore, a much milder procedure for the recovery of sorbed oil needs to be developed in order to recycle carbonized pith bagasse as well as the oil.

Using filtration under mild suction (by using a vacuum pump) of the sorbed carbonized pith bagasse, oils could be recovered without serious disruption of the bulky morphology of carbonized pith bagasse. 
The filtration process seemed to be practical because of the possibilities for recycling both oil and carbonized pith bagasse with reverse to the compression of the carbonized material when it couldn't be used again.

These results are in agreement with Toyoda and Inagaki (2000); they investigate the efficiency of recovery.

\subsection{Effect of particle size of combusted pith bagasse on the sorption capacity under simulated field conditions}

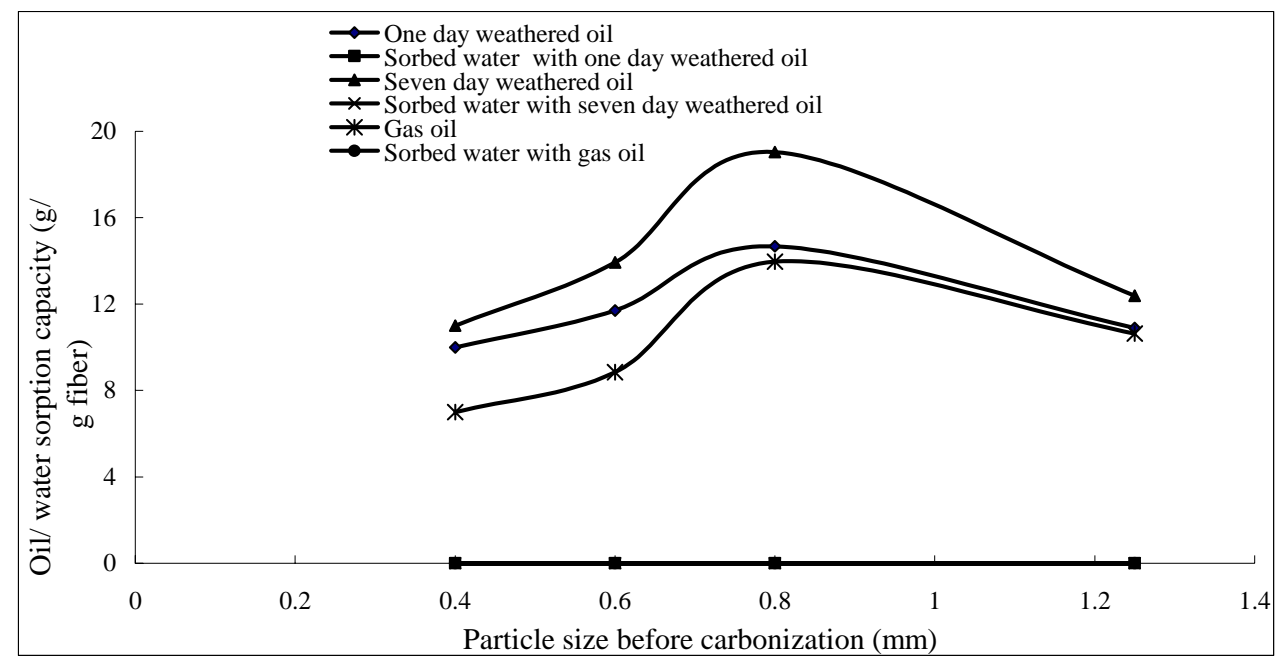

Figure 6. Effect of particle size of carbonized pith bagasse on the sorption capacity $\left(\mathrm{g} \mathrm{g}^{-1}\right.$ of fiber)

Figure 6 shows that decreasing the average particle size increases its oil sorption capacity, where an optimum is obtained at an average particle size of $0.8 \mathrm{~mm}$, but the oil sorption decreases back again.

Also the figure shows that the seven day weathered crude oil has the highest sorption capacity of (19.04 $\mathrm{g}$ oil g ${ }^{-1}$ fiber) at particle size of $0.8 \mathrm{~mm}$ then one day weathered oil (14.68 $\mathrm{g}$ oil $\mathrm{g}^{-1}$ fiber) and the gas oil has the lowest sorption capacity of (14 $\mathrm{g}$ oil g ${ }^{-1}$ fiber) this due variation in oil viscosity.

Adsorption is a surface phenomenon that is directly related to surface area. So increasing the surface area, the specific adsorption will increase.

Also Surface area affects the absorption of the material to a certain extent. As the surface area increases, it increases the capillaries that are being formed and hence increases the absorption.

Depending on the kind of absorbent, the holding areas can be divided into two zones,

a) Area between the particles/fibers: The oil held between the particles is due to the formation of capillaries, this kind of absorption (most commonly found), is called Capillary absorption.

b) Area within the particles/fibers: Some materials have a very unique structure that has tiny micro-pores in them and they serve as trap zones for fluids. This kind of absorption mechanism is called Micro-porous absorption. Bagasse absorbs oil both through capillaries and the micro-pores present in its structure.

The results are in agreement with Vitidsant et al. (1999) and Martinez et al. (2006); as they investigate the influence of size of material for carbonization on characteristic of activated carbon. They got that particle size reduction increases the sorption capacity of the activated carbon.

3.6. Comparison between the prepared sorbent from bagasse and commercial sorbents.

The results of these experiments are presented in Figure 7. 


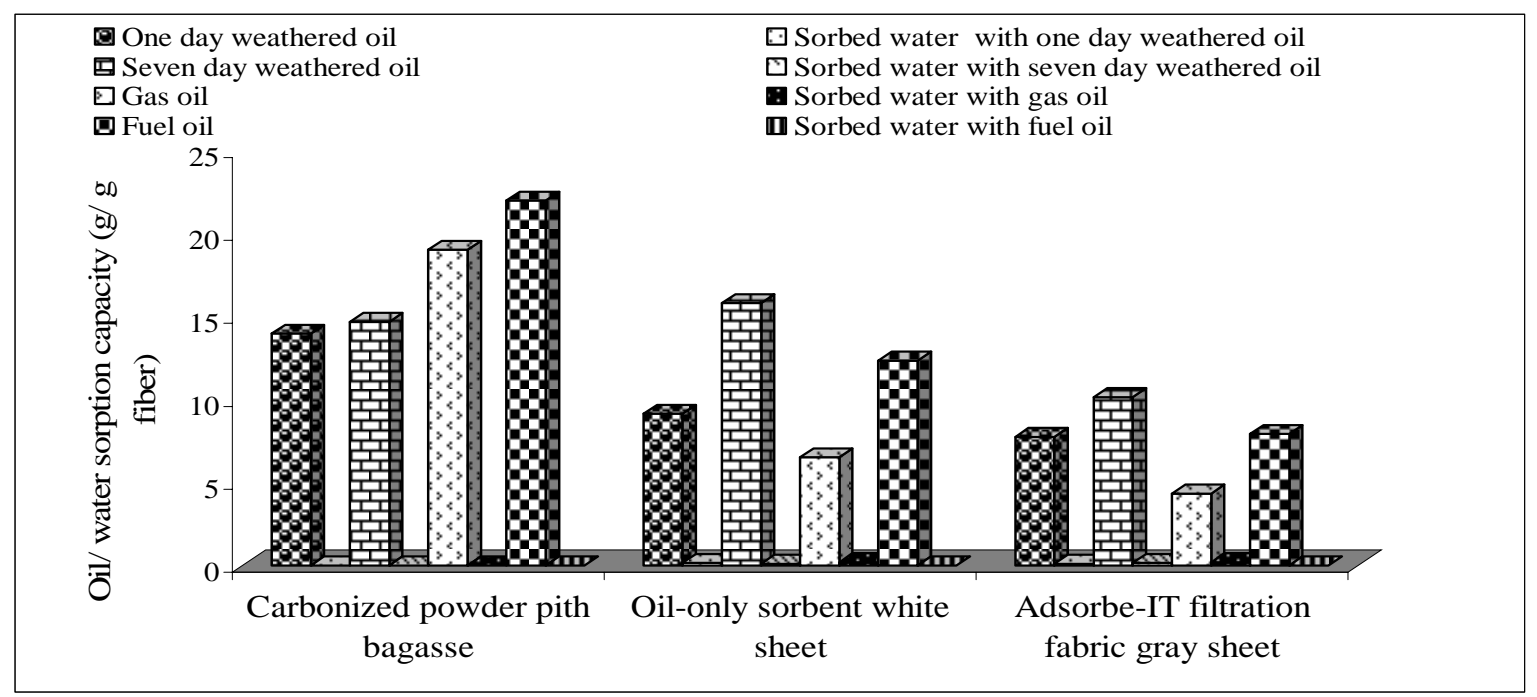

Figure 7. Comparison between prepared carbonized pith bagasse and commercial sorbent

The results show that the prepared carbonized pith bagasse has higher sorption capacity (of 22, $19.04,14.68$ and $13.97 \mathrm{~g} \mathrm{~g}^{-1}$ fiber) for fuel oil, seven day weathered oil, one day weathered oil and gas oil respectively than the commercial sorbents which have a maximum values for seven day weathered oil of (15.8125 and $10.15 \mathrm{~g} \mathrm{~g}^{-1}$ fiber) for Oil-only sorbent white sheet and Adsorbe-IT filtration fabric gray sheet respectively.

\section{CONCLUSION}

The behavior of sorption of heavy oils into carbonized pith bagasse was studied by using different kinds of oil with different viscosity under simulated field condition. The maximum sorption capacity of carbonized pith bagasse was found to be high, $19.06 \mathrm{~g}$ for the seven day weathered oil. Sorption capacity was found to depend strongly on the weight as it increases with increasing the weight of sorbent and with increasing the oil film thickness. The recovery of heavy oils sorbed into carbonized pith bagasse was performed using filtration under mild suction at room temperature, which seems to be a more practical process because carbonized pith bagasse can be recovered without serious disruption of its characteristically bulky morphology. However, the sorption capacity was found to decrease with its recycling. Comparative studies with a commercial sorbent material (Adsorbe-IT filtration fabric and Oilonly sorbent) demonstrated various advantages of the carbonized pith bagasse; the carbonized pith bagasse has a greater sorption capacity for oils.

\section{REFERENCES}

1. Amer A.A. and Hussein M., (2006). Bagasse as oil spill cleanup sorbent 2. Heavy oil sorption using carbonized pith bagasse fiber. The second International Conference on Health, Environment and Development, ICHEDII, Alexandria, Egypt.

2. ASTM (1998) D4007-81: Standard test method for water and sediment in crude oil by the centrifuge method. In: Annual Book of ASTM Standards. ASTM Committee on Standards, West Conshohocken, PA.

3. Choi H. and Cloud R.M. (1992) Natural sorbents in oil spill cleanup, Environmental Science and Technology, 26(4), 772-776.

4. Choi H.M. and Kwon H-J. (1993) Cotton nonwovens as oil spill cleanup sorbents, Textile Res.J., 63(4), 211-218.

5. Frankenfeld J.W. (1973) In: The Proceedings of Joint Conference on Prevention of Oil Spills. American Petroleum Institute, Washington, DC, 485-498.

6. Inagaki M., Kawahara A., Konno H. (2002) Sorption and recovery of heavy oils using carbonized fir fibers and recycling, Carbon, 40, 105-111.

7. Inagaki M., Shibata K., Setou S., Toyoda M. and Aizawa J-I. (2000) Sorption and recovery of heavy oils by using exfoliated graphite Part III Trials for practical applications, Desalination, 128, 219-222. 
8. Johnson R.F., Manjrekar T.G. and Halligan J.E. (1973) Removal of oil from water surfaces by sorption on unstructured fibers, Environ Sci Technol, 7, 439-43.

9. Jordan R.E. and Payne J.R. (1980) Fate and Weathering of Petroleum Spills in the Marine Environment: A Literature Review and Synopsis. Ann Arbor Science Publishers, Ann Arbor, MI.

10. Kawahara F.K. (1969) Identification and differentiation of heavy residual oil and asphalt pollutants in surface water by comparative ratios of infrared absorbances, Environ. Sci. Technol., 3, 150-153.

11. Larson R.A., Hunt L.L. and Blankendhip S.W. (1977) Formation of toxic products from a 2 fuel oil by photo oxidation, Environ. Sci. Technol., 13, 296-492.

12. Lim T-T. and Huang X. (2007) Evaluation of Kapok (ceiba pentandra (L.) Gaertn.) As a natural hollow hydrophobic-oleophilic fibrous sorbent for oil spill cleanup, Chemosphere, 66(5), 955-963.

13. Martinez M.L., Torres M.M., Guzmán C.A. and Maestri D.M. (2006) Preparation and characteristics of activated carbon from olive stones and walnut shells, Industrial Crops and Products, 23, 23-28.

14. Miyata N. (1999) Oil sorbency of sorbents prepared from Kenaf (Hibiscus cannabinus L.) plants. Sen'i Gakkaishi, 55, 576-583.

15. National Research Council (NRC) (1989) Using Oil Spill Dispersants on the Sea. National Academy Press, Washington, DC.

16. Payne J.R. and Phillips C.R. (1985) Photochemistry of petroleum, Environ. Sci. Technol., 19, 569-579.

17. Stlver W. and Meck D. (1984) Evaporation Rate of spills of hydrocarbons and petroleum mixtures, Environ. Sci. Technol., 18(11), 834-40.

18. Toyoda M. and Inagaki M. (2000) Heavy oil sorption using exfoliated graphite new application of exfoliated graphite to protect heavy oil pollution, Carbon, 38, 199-210.

19. Vitidsant T., Suravattanasakul T. and Damronglerd S. (1999) Production of Activated Carbon from Palm-Oil Shell by Pyrolysis and Steam Activation in a Fixed Bed Reactor, ScienceAsia, 25, 211-222.

20. Wardley-Smith J. (1983) The Control of Oil Pollution. Graham and Trotman Publication, London.

21. Wei Q.F., Mather R.R., Fotheringham A.F., Yang R.D. (2003) Evaluation of nonwoven polypropylene oil sorbents in marine oil spill recovery, Marine Pollution Bulletin, 46, 780-783.

22. Yamamoto H. (1998) Manufacturing of oil sorbent from heat treated wood fiber and developing new products, Cellulose Commun, 5, 148-151. 